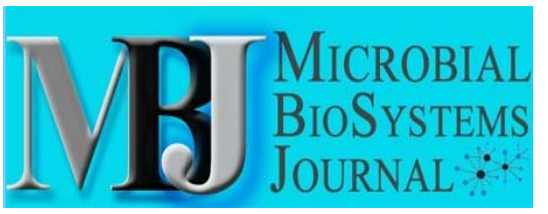

\title{
Anticancer potential of Hericium erinaceus extracts against particular human cancer cell lines
}

\section{Younis AM}

Department of Botany and Microbiology, Faculty of Science, Al Azhar University, Cairo, 11844, Egypt amyounis@mymail.vcu.edu

Younis AM 2017 - Anticancer potential of Hericium erinaceus extracts against particular human cancer cell lines. Microbial Biosystems 2(1), 9-20.

\begin{abstract}
Cancer is a leading cause of death worldwide. Cancer resulted in 8.2 million human deaths in 2012. It is expected that annual cancer cases will rise from 14 million in 2013 to 22 million within the next two decades. Mushrooms are extensively used as nutritional supplements in many countries. Moreover, mushrooms have many medicinal properties, including anticancer activity. In this study, the anticancer activity of different polar and non-polar extracts of Hericium erinaceus were evaluated against different human cancer cell lines including human liver carcinoma (Hep G2), the human colonic epithelial carcinoma (HCT 116), the human cervical cancer cells (HeLa) and the human breast adenocarcinoma (MCF-7) using 3-(4,5Dimethylthiazol-2-yl)-2,5-diphenyltetrazolium bromide (MTT) assay. Furthermore, as a control, the cytotoxicity effect of the different extracts were tested against isolated mouse hepatocytes. It was observed that the extracts by water and methanol from fresh and lyophilized fruiting bodies of $H$. erinaceus had the strongest anticancer effect. In contrast, the extracts by ether and ethyl acetate from mycelia and broth of $\mathrm{H}$. erinaceus showed lower anticancer activity against the tested carcinoma cell lines. The highest anticancer activity was recorded for aqueous extract of lyophilized fruiting bodies with half maximal inhibitory concentration $\left(\mathrm{IC}_{50}\right)$ values of $6.1 \pm 0.2$, $5.1 \pm 0.1,5.7 \pm 0.2$ and $5.8 \pm 0.3 \mu \mathrm{g} / \mathrm{ml}$ against Hep G2, HCT 116, HeLa and MCF-7 cells, respectively with non-significant effect on the normal mouse hepatocytes. To summarise, polar extracts of $H$. erinaceus can be good sources for isolating natural anticancer compounds. I recommend further chemical studies to isolate the active principles of the extract of $H$. erinaceus evaluated in the present.
\end{abstract}

Key words - Anticancer activity - Hericium erinaceus - monkey's head mushroom - mushroom extracts.

\section{Introduction}

Cancer is a leading cause of death worldwide. Cancer caused 8.2 million human deaths in (World Health Organization (WHO) 2012). By 2050, a 3-fold increase in incident cancer is estimated. The annual financial costs of cancer have been estimated at $\$ 1.16$ trillion US dollars per year as of 2012 (WHO 2014).

In the Egyptian context, according to the National Cancer Research Institute (NCRI) and Cancer Index, the chance of getting cancer before age 75 is around $15 \%$. People newly diagnosed with cancer number around 100,000 per year. Deaths from cancer are around 70,000 per year. The most common causes for both sexes together are liver $(24 \%)$, breast (15\%), and permits unrestricted use, distribution, and reproduction in any medium, provided the original author and source are credited. 
bladder (7\%). For Egyptian men, liver (34\%) and bladder (11\%) are the most common types while, for women the breast (32\%) and liver (14\%) as mentioned by various investigators (WHO 2012; Ibrahim 2014).

Treatment options often are expensive and will have side effects. For example, most chemotherapeutic agents for the treatment of cancer not only destroy tumors and stop cancer progress but also have an effect on the healthy cells and tissues. This situation has encouraged many scientists to search for natural products with anticancer activity to be more effective and safer agents to inhibit the growth of cancer cells (Younis et al. 2014a).

Experimental studies have demonstrated that many natural products from fungi have anticancer potential in a variety of bioassays systems and animal models (Evidente et al. 2014). Many mushrooms can be considered to be food of high nutritional value because they contain high quality proteins and most of the essential amino acids. They are also a good source of unsaturated fat, phosphorus, iron, and vitamins, including thiamine, riboflavin, ascorbic acid, ergosterol and niacin (Kalac 2009). Medicinal mushrooms have been used as traditional medicine for the treatment of various diseases due to their important therapeutic properties included, but not limited to, the anticancer activity (Wasser 2014).

Collectively, many researchers have investigated the antitumor activities of mushrooms and isolated mushroom metabolites with beneficial properties against cancer (Wu et al. 2011; Finimundy et al. 2013; Younis et al. 2014a, b).

Many polysaccharides isolated from mushrooms have strong antitumor activities (Moharib et al. 2014); for example, Lentinan which is a polysaccharide isolated from of Lentinula edodes and have strong anticancer activities has been used in the clinic for treating of several cancers, especially stomach cancer (Yamaguchi et al. 2011).

Hericium erinaceus has attracted the attention of many researchers due to its anti-cancer, hepatoprotictive and immunomodulatory effect (Patel and Goyal 2012). For example, Kim et al. (2011) investigated the anti-tumor effects of the $H$. erinaceus extracts in Balb/c mice transplanted with CT-26 colon cancer cells and observed that hot-water of fruiting bodies are rich with $\beta$-glucan which reduced tumor weights by $38 \%$ when injected daily for 2 weeks. In addition Li et al. (2014) isolated twenty-two compounds from $H$. erinaceus fractions and exhibited in vitro antitumor activities against liver cancer HepG2 and Huh-7, colon cancer HT29 , and gastric cancer NCI-87 cell lines and reported in vivo a significantly antitumor efficacy against all four xenograft models of HepG2, Huh-7, HT-29 and NCI-87 without toxicity to the host.

In this study, the anticancer activity of $H$. erinaceus extracts were evaluated against different human cancer cell lines using MTT assay. Furthermore, the cytotoxicity effect of $H$. erinaceus extracts were tested against isolated mouse hepatocytes.

\section{Materials and methods}

\section{H. erinaceus fruiting bodies and mycelia}

The fruiting bodies of $H$. erinaceus were collected from natural growth on trees trunk located at Richmond, Virginia, USA. Mycelia were isolated from the fruiting bodies and transferred to potato dextrose agar (PDA) medium, consisting of $4 \mathrm{~g} / \mathrm{L}$ potato extract (SigmaAldrich, Missouri, USA), 20 g/L dextrose (Pharmacia, New York, USA), 20 g/L agar (SigmaAldrich) (Younis et al. 2014a).

For liquid culture, the mycelia of $H$. erinaceus were grown in $250 \mathrm{ml}$ Erlenmyer flasks containing $100 \mathrm{ml}$ of a potato dextrose broth (PDB) medium consisting of $4 \mathrm{~g} / \mathrm{L}$ potato extract and $20 \mathrm{~g} / \mathrm{L}$ dextrose, and incubated at $24^{\circ} \mathrm{C}$ for 15 days. Then the mycelia were separated from the broth by filtration using $0.2 \mu \mathrm{m}$ filter, the filtrates were concentrated by lyophilization with a 
Virtis BT4KZL-105 lyophilizer (SP Industris, Warminster, PA, USA) and stored at $-20^{\circ} \mathrm{C}$ until use (Younis et al. 2015)

\section{Mushroom extracts}

The extraction was performed using polar solvent as distilled water and methanol (Sigma-Aldrich), and non-polar solvents ad ether (Sigma-Aldrich) and ethyl acetate (SigmaAldrich) on the fresh and lyophilized fruiting bodies as well as mycelia and broth.

The fresh fruiting bodies (FFB) were washed with distilled water, blot dried, cut into pieces, and immersed in the following solvents distilled water, methanol, ether or ethyl acetate at $10 \mathrm{~g} / 100 \mathrm{ml}(\mathrm{wt} / \mathrm{v})$, then stored in the refrigerator at $4^{\circ} \mathrm{C}$. After 24 hours the mixture was ground with a Waring commercial laboratory blender (Fisher Scientific, Inc., Waltham, MA, USA), and sonicated in an ultra-sonicator (Fisher Model 300 Sonic Dismembrator- Fisher Scientific, Inc., Waltham, MA, USA) for $30 \mathrm{~min}$ at $25 \mathrm{KHz}$. Then it was centrifuged at 10,000 xG for 20 minutes in (Beckman CS-6R Centrifuge- Beckman Coulter, Inc. Atlanta, GA, USA), then filtrated and the supernatants were collected. The water extract was concentrated by lyophilization. Other extracts were concentrated by air drying and re-suspended in dimethyl sulfoxide (DMSO) (Fisher) (Younis et al 2014a).

For the lyophilized fruiting bodies (LFB) the above method was used for the extractions using LFB at $10 \mathrm{~g} / 100 \mathrm{ml}(\mathrm{wt} / \mathrm{v})$

For mycelia extracts the mycelia were collected and washed with distilled water, blot dried, and the same method above was used for the extractions using LFB at $10 \mathrm{~g} / 100 \mathrm{ml}(\mathrm{wt} / \mathrm{v})$

For the broth extracts, the lyophilized broth was dissolved in distilled water, methanol, ether and ethyl acetate at $1 \mathrm{~g} / 10 \mathrm{ml}(\mathrm{wt} / \mathrm{v})$. The water extract was concentrated by lyophilization, other extracts were concentrated by air drying and resuspended in DMSO.

\section{Assay of anticancer activity of $\boldsymbol{H}$. erinaceus extracts against the carcinoma cells lines}

Four carcinoma cell lines were used to test the anticancer activity of $H$. erinaceus extracts, including human liver carcinoma cells (Hep G2) (ATCC ${ }^{\circledR}$ HB-8065 ${ }^{\mathrm{TM}}$ ) that cause hepatocellular carcinoma, the human colonic epithelial carcinoma (HCT 116) (ATCC ${ }^{\circledR}$ CCL$247^{\mathrm{TM}}$ ) that causes colorectal carcinoma, the human cervical cancer cells (HeLa) (ATCC ${ }^{\circledR}$ CCL$\left.2^{\mathrm{TM}}\right)$ from an adenocarcinoma and the human breast adenocarcinoma cells (MCF-7) $\left(\mathrm{ATCC}^{\circledR} \mathrm{HTB}^{\mathrm{N}} 22^{\mathrm{TM}}\right)$.

The four carcinoma cell lines were incubated in $75 \mathrm{~cm}^{2}$ culture corning flask (Fisher Scientific Inc., Loughborough, Leicestershire, United Kingdom) at $37^{\circ} \mathrm{C}$ in a water jacketed incubator (Forma Scientific series II, (Thermo Scientific Inc., Waltham, MA, USA) using their specific medium reported by American Type Culture Collection (ATCC). An inverted microscope (Olympus, CKX41; Shinjuku, Tokyo, Japan) was used to view the cell monolayer and confirm the absence of any contamination with bacteria and/or fungi. To count the number of cells, the cell monolayer was washed with $5 \mathrm{ml}$ phosphate buffer saline (PBS) without $\mathrm{Ca}^{2+/} \mathrm{Mg}^{2+}$ (Life Technologies) then $2.5 \mathrm{ml}$ of $0.53 \mathrm{mM}$ trypsin/EDTA (Life Technologies) was added to the culture flask, and incubated for 7-15 min. When cells were displaced from the flask, $6 \mathrm{ml}$ of maintenance media were added to stop the action of the trypsin. A hemocytometer was used to determine the number of viable cells using trypan blue staining (Life Technologies) (Younis et al. 2014b).

For anticancer assays, cells were suspended in medium at concentration $5 \times 10^{4}$ cell/well in $200 \mu \mathrm{l} /$ well in Corning 96-well tissue culture plates (Fisher Scientific Inc., UK), then incubated for $24 \mathrm{hr}$. Extracts were then dispensed in $50 \mu \mathrm{l}$ volumes into 96-well plates with six concentrations for each extract $=50,25,12.5,6.25,3.125,1.56 \mu \mathrm{g} / \mathrm{ml}$, and each concentration was repeated 5 times. Control with media or $0.5 \%$ DMSO were run for each 96 well plate. After incubating for $24 \mathrm{~h}$, the numbers of viable cells were determined by the MTT 3-(4,5dimethylthiazol-2-yl)-2,5-diphenyltetrazolium bromide (Sigma-Aldrich) test. This test was 
conducted as follows: the media was removed from the 96 well plate and replaced with $100 \mu$ of fresh culture RPMI 1640 medium without phenol red (Life Technologies) then $10 \mu \mathrm{l}$ of the 12 mM MTT stock solution ( $5 \mathrm{mg}$ of MTT in $1 \mathrm{~mL}$ of PBS) to each well including the untreated controls. The 96 well plates were then incubated at $37^{\circ} \mathrm{C}$ and $5 \% \mathrm{CO}_{2}$ for 4 hours. Then an $85 \mu \mathrm{l}$ aliquot of the media was removed from the wells, and $50 \mu \mathrm{l}$ of DMSO was added to each well and mixed thoroughly with the pipette and incubated at $37^{\circ} \mathrm{C}$ for $10 \mathrm{~min}$. The optical density was measured at $590 \mathrm{~nm}$ with the micro plate reader (Bio-TekuQuantmicroplate spectrophotometer BioTek, inc, Winooski, VT. USA). The anticancer activity was determined by the mean percent inhibition of the tumor cells remaining after the treatment by the following formula: (ODt/ODc) $\mathrm{x} 100 \%$ where ODt and ODc are the optical densities of wells with treated and untreated cells, respectively (Wu and Wang 2010; Elaasser et al. 2011; Younis et al 2014b). The half maximal inhibitory concentration $\left(\mathrm{IC}_{50}\right)$ was determined after plotting the dose response curve for each conc. using Graphpad Prism software (San Diego, CA. USA).

\section{Cytotoxicity assay}

$H$. erinaceus extracts were tested for cell toxicity using isolated normal mouse hepatocytes by a novel technique adopted by the author after Li et al. (2010). $21 \mathrm{~g}$ female mouse (Mus musculus C57/BL6) was euthanized by carbon dioxide for $1 \mathrm{~min}$, after death the mouse was placed onto a sterile tray and the fur on the abdomen was sprayed with a sterilized by $70 \%$ ethanol. Then a sterile lancet was used to cut the abdomen skin. The intestines moved to the right to uncover the portal vein and the vena cava. Then a $21 \mathrm{G}$ vein infusion set (Traverol laboratories Inc., Deerfield, IL. USA) inserted into the vena cava. The perfusion medium (I) consisting of $500 \mathrm{ml}$ sterile (PBS), $5 \mathrm{ml}$ of $1 \mathrm{M} \mathrm{HEPES}$ in $5 \%(\mathrm{w} / \mathrm{v}) \mathrm{KCl}$ buffer $(\mathrm{pH} 7.4), 2.5 \mathrm{ml}$ $1 \mathrm{M}$ of sterile and filtered glucose, $0.5 \mathrm{ml} 200 \mathrm{mM}$ EDTA (ethylene diamine tetra acetate), 0.5 $\mathrm{ml}$ phenol red solution, $\mathrm{pH}$ adjusted to 7.4 , were injected into the vena cava to perfuse through the liver. Finally the portal vein was cut to allow the blood to get out. The perfusion medium I was used for 10-15 min till the liver became clear of blood and turned white. Then the collagenase solution was used for approximately $10 \mathrm{~min}$. The entire liver was removed to a sterile petri dish containing perfusion medium (II) consisting of $500 \mathrm{ml}$ sterile PBS, $5 \mathrm{ml} 1 \mathrm{M}$ HEPES in 5\% (w/v) $\mathrm{KCl}$ buffer $(\mathrm{pH} 7.4), 10 \mathrm{ml} 1 \mathrm{M}$ HEPES, $2.5 \mathrm{ml} 1 \mathrm{M}$ glucose (sterile filtered), $1 \mathrm{ml} 500 \mathrm{mM} \mathrm{CaCl} 2,0.5 \mathrm{ml}$ phenol red solution, $\mathrm{pH}$ adjusted to 7.4, and the liver was cut into small pieces using two sterile pairs of forceps. The crude hepatocyte, in the perfusion medium (II), was then filtered through a gauze mesh filter $(100 \mu \mathrm{m}$ in diameter) and transferred the resulting cell suspension into $50 \mathrm{ml}$ sterile tubes and centrifuged at $1050 \mathrm{rpm}$ for $2 \mathrm{~min}$. The supernatant discarded and the parenchymal hepatocytes were washed three times using the same procedure by resuspending the pellet each time in fresh perfusion medium II and centrifuging at $1050 \mathrm{rpm}$ for $2 \mathrm{~min}$. Then the hepatocytes were resuspended in $30 \mathrm{ml}$ Williams $\mathrm{E}$ culture medium consisting of Williams E medium with L-glutamine, supplemented with $10 \%(\mathrm{v} / \mathrm{v})$ heatinactivated fetal bovine serum (FBS), $1 \%(\mathrm{v} / \mathrm{v})$ pen/step, $1 \%(\mathrm{v} / \mathrm{v})$ nonessential amino acids and $2.2 \mathrm{~g} / \mathrm{L}$ sodium bicarbonate. The hepatocytes were checked for cell numbers and viability using trypan blue and a hemocytometer (Li et al. 2010). The isolated normal mouse hepatocytes were suspended in medium at concentration $5 \times 10^{4}$ cell/well and $200 \mu \mathrm{l} /$ well dispensed into Corning ${ }^{\circledR}$ 96-well tissue culture plates then incubated for $24 \mathrm{hr}$ at $37{ }^{\circ} \mathrm{C}$ in a water jacketed double door incubator under $5 \% \mathrm{CO}_{2}$. After the inoculation, the cells were viewed using an inverted microscope to view the cell viability and confirmed the absence of any contamination with bacteria and/or fungi and now ready for the cytotoxicity assay.

For each $H$. erinaceus extract, six different concentrations (five replica each) of 50, 25, $12.5,6.25,3.125,1.56 \mu \mathrm{g} / \mathrm{ml}$ were prepared, and then dispensed into 96-well plates at $50 \mu 1$ per well. The 96-well plates were incubated at $37^{\circ} \mathrm{C}$ in a humidified incubator with $5 \% \mathrm{CO}_{2}$ for a period of $24 \mathrm{~h}$ with a control of untreated cells. The numbers of viable cells were determined by 
MTT as previously mentioned before and the percentage of inhibition was calculated as [1-(ODt/ODc)]x100\% where ODt is the mean optical density of wells treated with the tested compounds and ODc is the mean optical density of untreated cells (Li et al. 2010).

\section{Results}

The anticancer activity of $H$. erinaceus extracts against the four carcinoma cell lines and the cytotoxicity of these extracts against the isolated normal mouse hepatocytes is displayed in Table 1. The highest anticancer effect was reported by the aqueous extract of lyophilized fruiting bodies with maximal inhibition percentage (MPI) of $92 \pm 2.1,96.1 \pm 1.5,94.2 \pm 2.6$ and $95.5 \pm 2.3 \%$ with half maximal inhibitory concentration $\left(\mathrm{IC}_{50}\right)$ values of $6.1 \pm 0.2,5.1 \pm 0.1,5.7 \pm 0.2$ and $5.8 \pm 0.3 \mu \mathrm{g} / \mathrm{ml}$ against Hep G2, HCT 116, HeLa and MCF-7 cells, respectively with nonsignificant effect (MPI $=6.6 \pm 0.8) \%$ on the normal mouse hepatocytes $6.6 \pm 0.8$.

Also, the methanol of LFB showed high anticancer effect with MPI of 85.1 \pm 2.7 , $87.3 \pm 2.8,86.2 \pm 2.9$ and $83.1 \pm 1.9 \%$ and $\mathrm{IC}_{50}$ of $15.1 \pm 1.7,9.7 \pm 0.811 .1 \pm 0.8$, and $8.5 \pm 0.9 \mu \mathrm{g} / \mathrm{ml}$ against Hep G2, HCT 116 HeLa and MCF-7 cells, respectively. Followed by the aqueous of FFB which showed high MPI of $83 \pm 2.1,75.8 \pm 1.2,79.4 \pm 2.5$ and $77.1 \pm 1.9 \%$ with $\mathrm{IC}_{50}$ of $7.9 \pm 0.9$, $11.7 \pm 0.9,10.7 \pm 1.8$ and $12.5 \pm 1.9 \mu \mathrm{g} / \mathrm{ml}$ against Hep G2, HCT 116, HeLa and MCF-7 cells, respectively. In addition, both methanol extract of LFB and aqueous extract of FFB reported low cytotoxicity effect against the isolated mouse hepatocytes wit MPI $11.3 \pm 1.1$ and $8.3 \pm 1.1 \%$ respectively (Table 1, Figures 1-5).

Furthermore, the methanol extract of FFB reported high MPI against the four carcinoma cells and low MPI against normal mouse hepatocytes with MPI of 74.7 $\pm 1.4,71.1 \pm 2.1,64.9 \pm 1.2$, $68.8 \pm 2.1$ and $12.5 \pm 1.9 \%$ against Hep G2, HCT $116 \mathrm{HeLa}, \mathrm{MCF}-7$ and normal mouse hepatocytes, respectively (Table 1, Figures 1-5).

In comparison, ether and ethyl acetate extracts showed less effect than the aqueous and methanol extracts against the four carcinoma cells. The ether and ethyl acetate of both FFB and LFB had approximately the same ranges of MPI (43-33\%) and $\mathrm{IC}_{50}(60-91 \mu \mathrm{g} / \mathrm{ml})$ against most tumor cell lines and approximately the highest effect reported in this study against the isolated normal mouse hepatocytes with MPI ranges between (32-29) \%.

In contrast, extracts from mycelia and broth showed lower anticancer activities than extracts from FFB and LFB. the highest effect was observed by the aqueous extract of mycelia and showed MPI of $67.6 \pm 3.2,73.5 \pm 1.8,71.3 \pm 1.9$ and $76.6 \pm 3.2 \%$ and $\mathrm{IC}_{50}$ of $31.2 \pm 2.2$, $29.9 \pm 1.7,28.8 \pm 1.8$ and $25.2 \pm 2.2 \mu \mathrm{g} / \mathrm{ml}$ against Hep G2, HCT $116 \mathrm{HeLa}$ and MCF-7 cells, respectively. Non-significant effect with $10.5 \%$ MPI was observed against the normal mouse hepatocytes.

Both aqueous extract of broth and methanol extract of mycelia or broth showed approximately the same MPI ranges between (53-43) \% with $\mathrm{IC}_{50}$ ranged between (53-43) $\mu \mathrm{g} / \mathrm{ml}$. the effect of these extracts on the isolated normal mouse hepatocytes was varied and showed $7.1 \%$ by water extract of broth and $14.6 \%$ by methanol extract of broth (Table 1 , Figures 1-5).

Finally, the ether and ethyl acetate extracts from mycelia and broth showed low effect on the four carcinoma cells and higher effect against normal mouse hepatocytes.

The lowest effect observed by the EE of broth with MPI of $7.2 \pm 0.2 \%$ against Hela cells with estimated $\mathrm{IC}_{50} 336 \pm 5.1$ (Table 1). 
Table 1 The anticancer activities of $H$. erinaceus extracts against the four carcinoma cell lines and the cytotoxicity effect against the isolated normal mouse hepatocyte

\begin{tabular}{|c|c|c|c|c|c|c|c|c|c|c|}
\hline \multirow{2}{*}{ Sample } & \multirow{2}{*}{ Solvent } & \multicolumn{2}{|c|}{ HepG2 } & \multicolumn{2}{|c|}{ HCT 116} & \multicolumn{2}{|c|}{ HeLa } & \multicolumn{2}{|c|}{ MCF-7 } & \multirow{2}{*}{$\begin{array}{c}\text { Normal } \\
\text { mouse } \\
\text { hepatocyte } \\
\text { Maximum } \\
\text { inhibitory } \\
\%\end{array}$} \\
\hline & & $\begin{array}{c}\text { Maximum } \\
\text { inhibitory \% }\end{array}$ & $\mathrm{IC}_{50}(\mu \mathrm{g} / \mathrm{ml})$ & $\begin{array}{c}\text { Maximum } \\
\text { inhibitory \% }\end{array}$ & $\mathrm{IC}_{50}(\mu \mathrm{g} / \mathrm{ml})$ & $\begin{array}{c}\text { Maximum } \\
\text { inhibitory \% }\end{array}$ & $\begin{array}{c}\mathrm{IC}_{50} \\
(\mu \mathrm{g} / \mathrm{ml})\end{array}$ & $\begin{array}{c}\text { Maximum } \\
\text { inhibitory \% }\end{array}$ & $\begin{array}{c}\mathrm{IC}_{50} \\
(\mu \mathrm{g} / \mathrm{ml})\end{array}$ & \\
\hline \multirow{4}{*}{$\begin{array}{c}\text { Fresh } \\
\text { fruiting } \\
\text { bodies }\end{array}$} & Water & $83 \pm 2.1$ & $7.9 \pm 0.9$ & $75.8 \pm 1.2$ & $11.7 \pm 0.9$ & $79.4 \pm 2.5$ & $10.7 \pm 1.8$ & $77.1 \pm 1.9$ & $12.5 \pm 0.9$ & $8.3 \pm 1.1$ \\
\hline & Methanol & $74.7 \pm 1.4$ & $15.1 \pm 1.3$ & $71.1 \pm 2.1$ & $21.8 \pm 1.7$ & $64.9 \pm 1.2$ & $26.1 \pm 2.1$ & $68.8 \pm 2.1$ & $24.3 \pm 2.4$ & $12.5 \pm 1.9$ \\
\hline & Ether & $33.1 \pm 2.8$ & $86.7 \pm 3.8$ & $35.3 \pm 2.1$ & $73.1 \pm 2.4$ & $33.7 \pm 2.6$ & $91.2 \pm 2.3$ & $40.7 \pm 2.2$ & $81.3 \pm 2.6$ & $32.3 \pm 2.2$ \\
\hline & Ethyl Acetate & $35 \pm 1.7$ & $69.1 \pm 3.1$ & $34.6 \pm 1.8$ & $64.2 \pm 2.3$ & $43.4 \pm 2.5$ & $65.6 \pm 2.3$ & $39.3 \pm 2.0$ & $62.9 \pm 2.3$ & $29.6 \pm 2.7$ \\
\hline \multirow{4}{*}{$\begin{array}{l}\text { Lyophilized } \\
\text { fruiting } \\
\text { bodies }\end{array}$} & Water & $92 \pm 2.1$ & $6.1 \pm 0.2$ & $96.1 \pm 1.5$ & $5.1 \pm 0.1$ & $94.2 \pm 2.6$ & $5.7 \pm 0.2$ & $95.5 \pm 2.3$ & $5.8 \pm 0.3$ & $6.6 \pm 0.8$ \\
\hline & Methanol & $85.1 \pm 2.7$ & $15.1 \pm 1.7$ & $87.3 \pm 2.8$ & $9.7 \pm 0.8$ & $86.2 \pm 2.9$ & $11.1 \pm 0.8$ & $83.1 \pm 1.9$ & $8.5 \pm 0.9$ & $11.3 \pm 1.1$ \\
\hline & Ether & $42.2 \pm 1.2$ & $68.5 \pm 2.5$ & $41.1 \pm 2.5$ & $67.4 \pm 2.3$ & $43.2 \pm 2.2$ & $60 \pm 1.7$ & $37.8 \pm 1.9$ & $68.5 \pm 2.6$ & $23.2 \pm 1.2$ \\
\hline & Ethyl Acetate & $33.9 \pm 1.5$ & $63.9 \pm 3.5$ & $37.6 \pm 2.9$ & $63.1 \pm 2.8$ & $39.6 \pm 2.2$ & $63.7 \pm 2.3$ & $43.6 \pm 1.9$ & $56.6 \pm 1.7$ & $21.1 \pm 2.1$ \\
\hline \multirow{4}{*}{ Mycelia } & Water & $67.6 \pm 3.2$ & $31.2 \pm 2.2$ & $73.5 \pm 1.8$ & $29.9 \pm 1.7$ & $71.3 \pm 1.9$ & $28.8 \pm 1.8$ & $76.6 \pm 3.2$ & $25.2 \pm 2.2$ & $10.5 \pm 0.9$ \\
\hline & Methanol & $50.9 \pm 1.9$ & $45.9 \pm 1.9$ & $52 \pm 2.5$ & $50.9 \pm 2.1$ & $53 \pm 2.4$ & $42.9 \pm 2.1$ & $53.2 \pm 3.5$ & $44.1 \pm 2.5$ & $13.8 \pm 2.1$ \\
\hline & Ether & $21.2 \pm 1.6$ & $97.5 \pm 4.7$ & $31 \pm 1.9$ & $87.5 \pm 1.8$ & $26.1 \pm 1.2$ & $128 \pm 4.1$ & $21.2 \pm 1.6$ & $117.5 \pm 4.7$ & $31 \pm 1.7$ \\
\hline & Ethyl Acetate & $28.2 \pm 1.5$ & $103.2 \pm 2.3$ & $34.1 \pm 2.1$ & $99.1 \pm 2.3$ & $25 \pm 1.4$ & $125 \pm 3.3$ & $30.2 \pm 1.5$ & $93.2 \pm 4.3$ & $29.1 \pm 2.1$ \\
\hline \multirow{4}{*}{ Broth } & Water & $52.2 \pm 1.2$ & $48.5 \pm 2.1$ & $44.1 \pm 2.5$ & $55.4 \pm 2.3$ & $43.2 \pm 2.2$ & $50 \pm 3.7$ & $43.2 \pm 1.2$ & $52.5 \pm 2.5$ & $7.1 \pm 0.5$ \\
\hline & Methanol & $43.9 \pm 1.5$ & $53.9 \pm 3.5$ & $43.6 \pm 2.9$ & $53.1 \pm 2.1$ & $49.6 \pm 2.2$ & $43.7 \pm 1.3$ & $49.9 \pm 1.5$ & $50.9 \pm 3.5$ & $14.6 \pm 0.9$ \\
\hline & Ether & $13.2 \pm 1.2$ & $272 \pm 3.5$ & $21.3 \pm 1.1$ & $179.5 \pm 2.9$ & $7.2 \pm 0.2$ & $336 \pm 5.1$ & $22.7 \pm 2.1$ & $127.3 \pm 2.8$ & $19.2 \pm 1.2$ \\
\hline & Ethyl Acetate & $25.1 \pm 2.5$ & $372 \pm 7.1$ & $20 \pm 1.2$ & $177.4 \pm 2.7$ & $17.2 \pm 0.9$ & $196 \pm 3.2$ & $24.8 \pm 2.1$ & $152.8 \pm 2.3$ & $28.1 \pm 2.1$ \\
\hline
\end{tabular}

The data are expressed as the mean values $\pm \mathrm{SD}$; The maximal inhibition percentage of tumor cells determined with $50 \mu \mathrm{g} / \mathrm{ml}$ of each extract. IC 50 was determined from a range of concentrations shown in Figures 1-5 using Graphpad Prism software. 

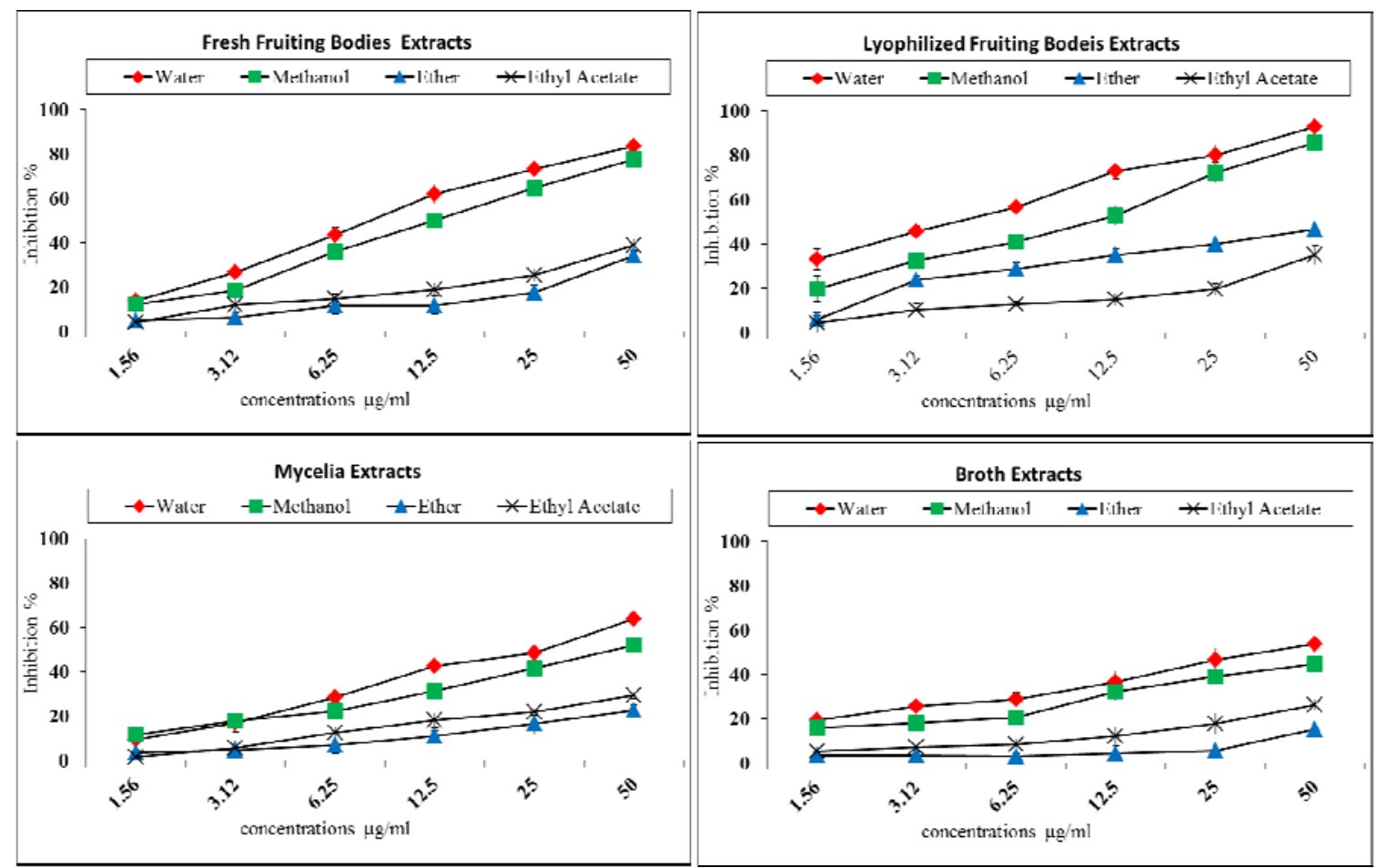

Fig. 1- The anticancer activity of H. erinaceus extracts against Hep G2 cell line showing the effect of extract concentrations tested at 50, 25, 12.5, 6.25, 3.125 and $1.56 \mu \mathrm{g} / \mathrm{ml}$.
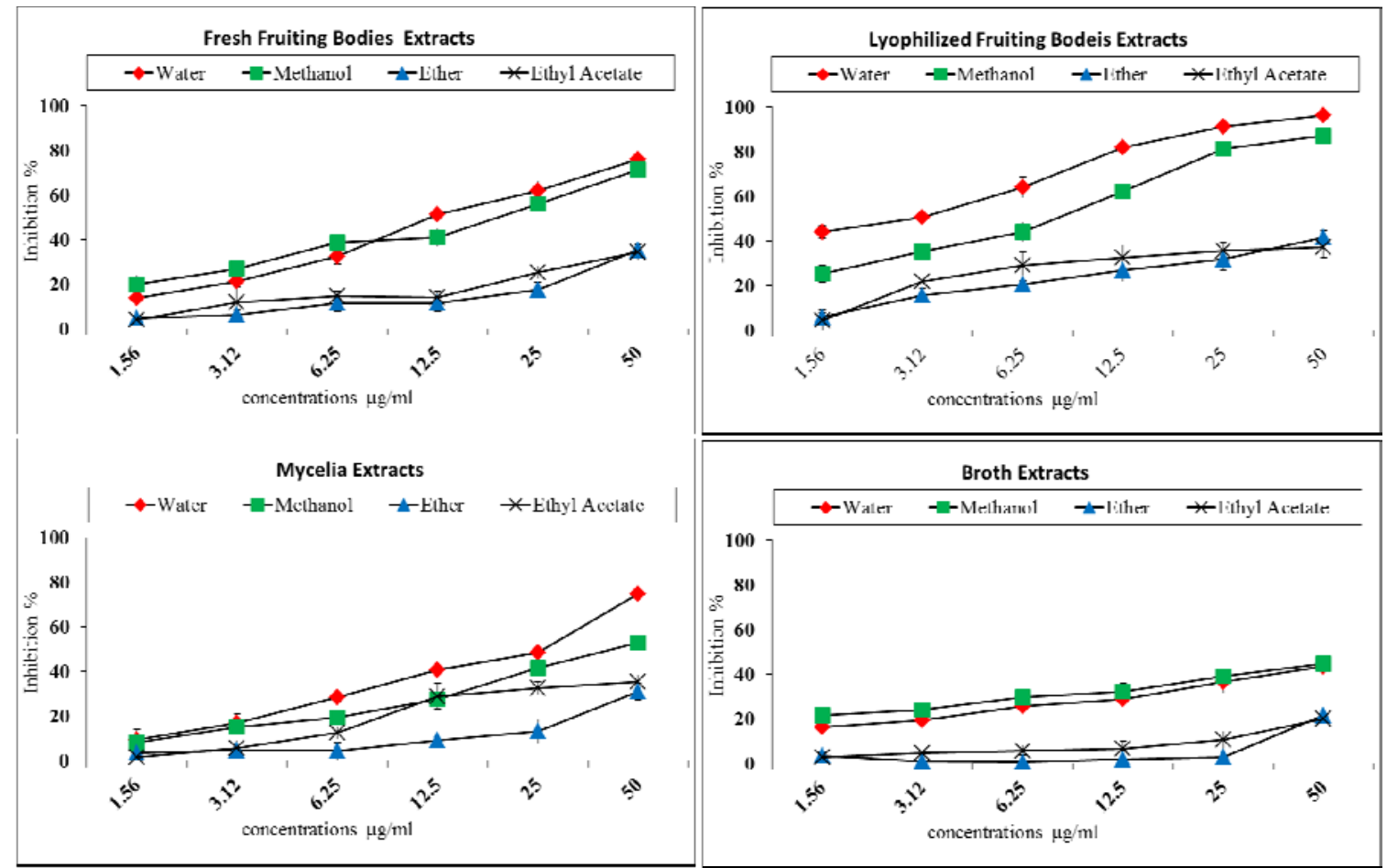

Fig. 2- The anticancer activity of $H$. erinaceus extracts against HCT 116 cell line showing the effect of extract concentrations tested at 50, 25, 12.5, 6.25, 3.125 and $1.56 \mu \mathrm{g} / \mathrm{ml}$. 

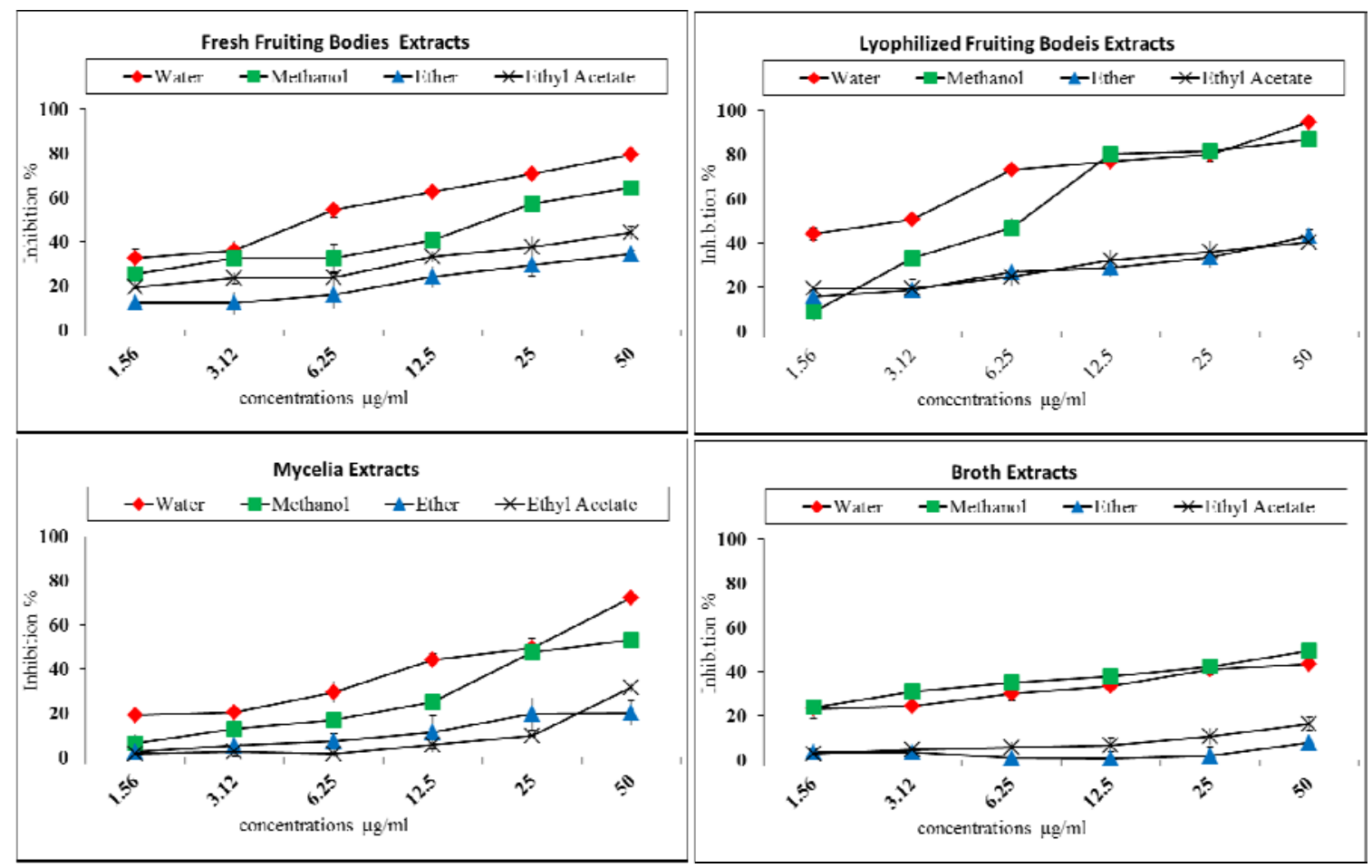

Fig. 3- The anticancer activity of $H$. erinaceus extracts against HeLa cell line showing the effect of extract concentrations tested at 50, 25, 12.5, 6.25, 3.125 and $1.56 \mu \mathrm{g} / \mathrm{ml}$.
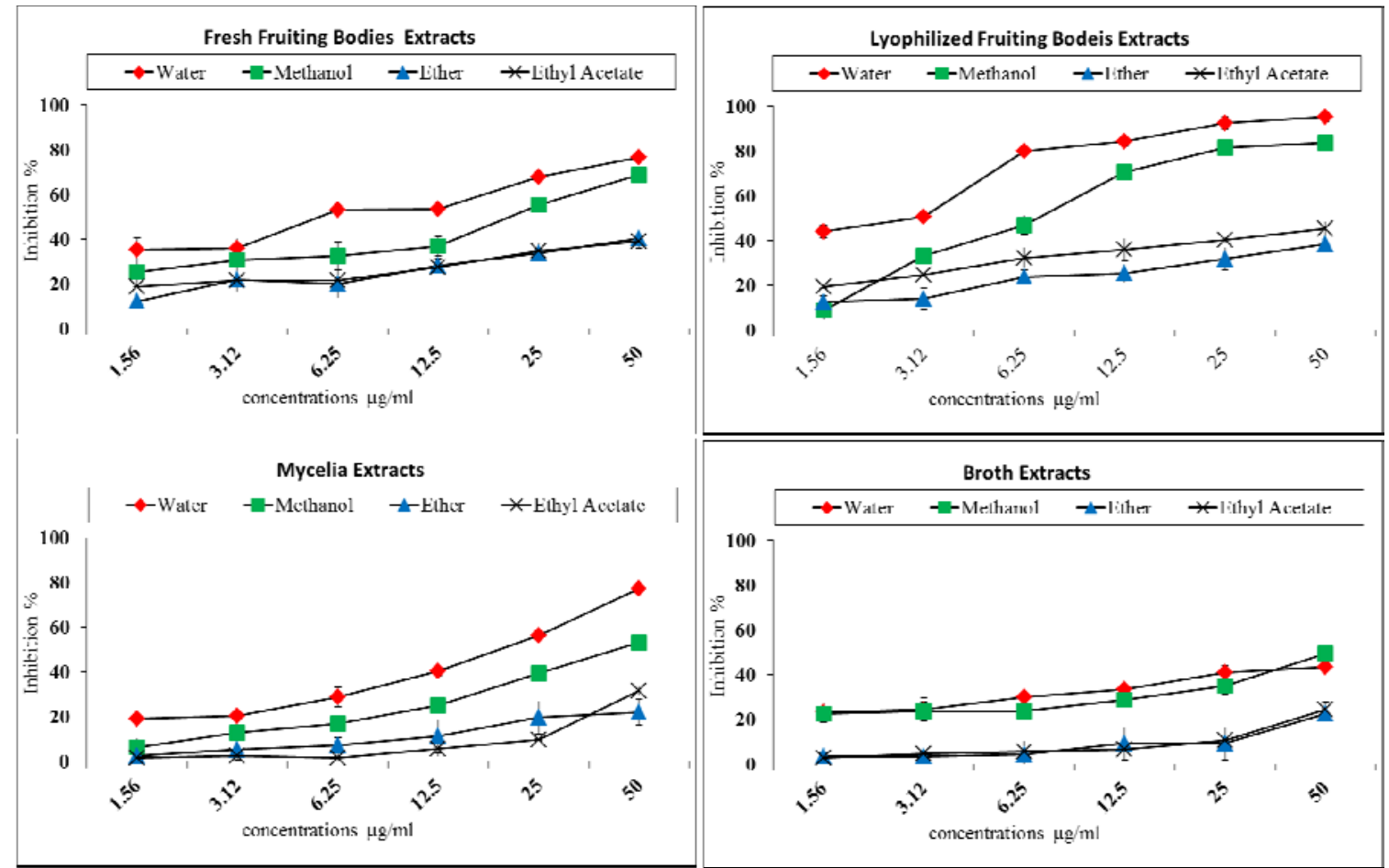

Fig. 4- The anticancer activity of $H$. erinaceus extracts against MCF-7 cell line showing the effect of extract concentrations tested at 50, 25, 12.5, 6.25, 3.125 and $1.56 \mu \mathrm{g} / \mathrm{ml}$. 

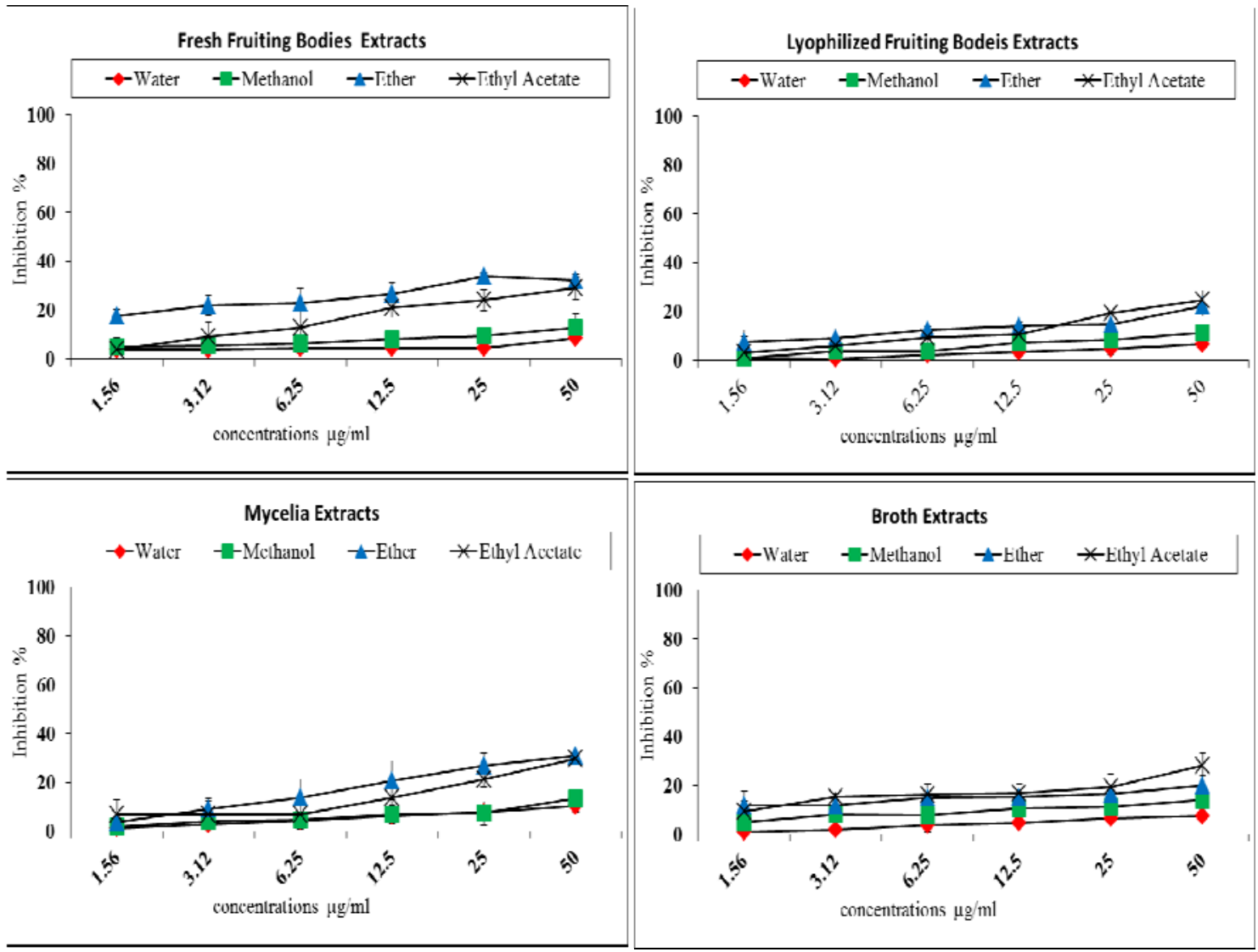

Fig. 5- The cytotoxicity effect of $H$. erinaceus extracts against isolated mouse hepatocytes showing the effect of extract concentrations tested at 50, 25, 12.5, 6.25, 3.125 and 1.56 $\mu \mathrm{g} / \mathrm{ml}$.

\section{Discussion}

Cancer, also known as malignancy, is an uncontrolled growth of cells. There are more than 100 types of cancer, including breast, skin, lung, colon, prostate, and lymphoma cancer. Unfortunately cancer treatment often includes one or more of chemotherapy, radiation and surgery. These treatment options are relatively expensive, unstable, and sometimes have undesirable pharmacological actions and limited range activities (Younis et al. 2014a). Medicines from the natural sources usually have lower side effects. Natural products have been the source of a majority of therapeutic agents in modern medicine (Newman 2007). Collectively, many natural products used as important sources of anti-cancer lead molecules. Moreover, many successful anti-cancer drugs are natural products or their analogues. Many more are under clinical trials (Mondal et al. 2012).

In this study, different $H$. erinaceus extracts was tested for their anticancer activity against different human cancer cell lines and tested for their cytotoxicity effect against isolated mouse hepatocytes. Results demonstrated that $H$. erinaceus extracts can be a good source for anticancer substances, and these results are consistent with reports indicating that mushrooms extracts had anticancer effects. For example, low-molecular weight substances isolated from mushrooms have been studied and reported to have anticancer activates (Petrova 2012).

In recent years, much attention has been focused on polysaccharides isolated from mushrooms (Jwanny et al. 2002; Moharib et al. 2014; Yamaguchi et al. 2011). In this study, it 
was observed that LFB extracts were the most potent extracts with anticancer activity followed by the FFB extracts. In Contrast, the extracts from mycelia and broth had lower anticancer activities than the LFB and FFB extracts of $H$. erinaceus against the four carcinoma cell lines.

Numerous studies have reported the potential medicinal values or health beneficial activities of $H$. erinaceus, like anti-cancer, anti-hypertensive, hypolipidemic, neuronal disease protecting activities (Khan et al. 2013). Other researchers demonstrated that $H$. erinaceus polysaccharides possess anti-cancer activities.

Lee and Hong (2010) demonstrated that $H$. erinaceus polysaccharides act as an enhancer to sensitize doxorubicin (Dox)-mediated apoptotic signaling and suggested that $H$. erinaceus polysaccharides in combination with Dox serves as an effective tool for treating drug-resistant human hepatocellular carcinoma.

In this study, the water extract of LFB showed the highest anticancer effect with MPI of $92 \pm 2.1,96.1 \pm 1.5,94.2 \pm 2.6$ and $95.5 \pm 2.3 \%$ with $\mathrm{IC}_{50}$ values of $6.1 \pm 0.2,5.1 \pm 0.1,5.7 \pm 0.2$ and $5.8 \pm 0.3 \mu \mathrm{g} / \mathrm{ml}$ against Hep G2, HCT 116, HeLa and MCF-7 cells, respectively and showed nonsignificant effect on the normal mouse hepatocytes $6.6 \pm 0.8 \%$. This result is in accordance with results reported by Lee et al. (2009) who found that the crude water-soluble polysaccharide of $H$. erinaceus with anticancer activity due to it up-regulated some functional immuno-modulating events mediated by activated macrophages.

Furthermore, polar solvent extracts showed non-significant effect on the normal mouse hepatocytes, the water extracts of all parts of $H$. erinaceus showed the lowest cytotoxicity effect against the isolated normal mouse hepatocytes with MPI ranged between (6.6-10.5) \% followed by the methanol extract with MPI (11.3-14.6) \%. On the other hand, non-polar solvent extracts reported higher cytotoxicity against the isolated normal mouse hepatocytes with MPI ranged between (19-32) \%.

This result is in accordance with previous study reported that water extract of LFB of $H$. erinaceus exhibited hepatoprotective effect against ethanol-induced gastric ulcers in rats (Abdulla et al. 2008). In addition, Zhang et al. (2012) reported that the ethanoic extract of endopolysaccharides from $H$. erinaceus mycelia grown on tofu had antioxidant potential and hepatoprotective activity.

This hepatoprotective effect may be due to its high antioxidant capacity. Therefore The $H$. erinaceus polysaccharides could be used as antioxidant product and a supplement in the prevention of hepatic diseases. Also Hao et al. (2015) demonstrated that that the aqueous extract of $H$. erinaceus had a relatively significant effect on the hepatic histopathological observations in mice model, which had alcoholic liver damage.

The conclusion based on the data available for this study is that $H$. erinaceus extracts may well represent a practical and promising approach for cancer prevention and cancer treatment with non-significant effect on the isolated mouse hepatocytes which gives the possibility of using the $H$. erinaceus extracts as anticancer and hepatoprotective drugs. Epidemiological, histopathological and clinical studies need to be carried out to identify other molecular targets; resolve the relationships between $H$. erinaceus extracts intake and cancer risks; and determine the optimum dosing, efficacy, and safety alone and in combination with chemotherapy and/or radiotherapy. Additionally, more chemical studies will be needed to isolate and identify the active principles of the extract of $H$. erinaceus evaluated in the present. I believe that it is worthwhile to exploit the potential of these antitumor compounds in treating the cancer diseases.

The present article is presented in the ' 1 st International Conference on Fungal Conservation in the Middle East and North of Africa, Ismailia, Egypt, 18-20 October 2016. 


\section{Acknowledgements}

The author is grateful to Dr. Fang-Sheng Wu, Dr. Jennifer Stewart and Dr. John J. Ryan from department of Biology, Virginia Commonwealth University for advice and assistance with technical procedures.

\section{References}

Abdulla M. A. Noor S. M., Sabaratnam V., Abdullah N., Wong K.H. and Ali H. M. 2008. Effect of culinary-medicinal lion's mane mushroom Hericium erinaceus (Bull.: Fr.) Pers. (Aphyllophoromycetideae), on ethanol-induced gastric ulcers in rats. International Journal of Medicinal mushrooms 10(4):325-330.

Elaasser M. M., Abdel-Aziz M. M. and El-Kassas R. A. 2011. Antioxidant, antimicrobial, antiviral and antitumor activities of pyranone derivative obtained from Aspergillus candidus. Journal of Microbiology and Biotechnology Research 1:5-17.

Evidente A., Kornienko A., Cimmino A., Andolfi A., Lefranc F., Mathieud V. and Kiss R. 2014. Fungal metabolites with anticancer activity. Natural Product Reports 31:617627.

Finimundy T. C., Gambato G., Fontana R., Camassola M., Salvador M., Moura S., Hess J., Henriques J. A., Dillon A. J. and Roesch-Ely M. 2013. Aqueous extracts of Lentinula edodes and Pleurotus sajor-caju exhibit high antioxidant capability and promising in vitro antitumor activity. Nutrition Research, 33:76-84.

Hao L., Xie Y., Wu G., Cheng A., Liu X., Zheng R., Huo H. and Zhang J. 2015. Protective effect of Hericium erinaceus on alcohol induced hepatotoxicity in mice. Evidence-Based Complementary and Alternative Medicine article ID:418023.

Ibrahim A., Khaled H., Mikhail N., Baraka H. and Kamel H. 2014. Cancer Incidence in Egypt: Results of the National Population-Based Cancer Registry Program. Journal of Cancer Epidemioogy article ID 437971, doi:10.1155/2014/437971.

Jwanny E. W., Esmat A. Y., Rashad M. M., Daba A. S. and Abdel-Fattah M. M. 2002. Antitumor activity of polysaccharides extracted from Pleurotus ostreatus fruiting bodies and mycelia cultivated on date waste. The Egyption Journal of Biochemistry and Molecular Biology 20:23-40.

Kalac P. 2009. Chemical composition and nutritional value of European species of wild growing mushrooms. Food Chemistry 113: 9-16.

Khan A. M., Tania M., Liu R. and Rahman M. M. 2013. Hericium erinaceus: an edible mushroom with medicinal values. Journal of Complementary and Integrative Medicine 10(1): $1-6$

Kim S. P., Kang M. Y., Kim J. H., Nam S. H. and Friedman M. 2011. Composition and mechanism of antitumor effects of Hericium erinaceus mushroom extracts in tumorbearing mice. Journal of Agriculture and Food Chemistry 59(18):9861-9.

Lee J. S. and Hong E. K. 2010. Hericium erinaceus enhances doxorubicin-induced apoptosis in human hepatocellular carcinoma cells. Cancer Letter, 297(2):144-54.

Lee J. S., Min K. M., Cho J. Y. and Hong E. K. 2009. Study of macrophage activation and structural characteristics of purified polysaccharides from the fruiting body of Hericium erinaceus. Journal of Microbiology and Biotechnology 19:951-9.

Li G., Yu K., Li F., Xu K, Li J., He S., Cao S. and Tan G. 2014. Anticancer potential of Hericium erinaceus extracts against human gastrointestinal cancers. Journal of Ethnopharmacology 153(2):521-30.

Li W. K., Ralphs L. and Tosh D. 2010. Isolation and Culture of Adult Mouse Hepatocytes. Book Mouse Cell Culture, Methods in Molecular Biology. Chapter 13:185-195 
Moharib S. A., Maksoud N. A., Ragab H. M. and Shehata M. M. 2014. Anticancer activities of mushroom polysaccharides on chemically-induced colorectal cancer in rats. Journal of Applied Pharmaceutical Science 4: 54-63.

Mondal S., Bandyopadhyay S., Ghosh M. K., Mukhopadhyay S., Roy S. and Mandal C. 2012. Natural products: promising resources for cancer drug discovery. Anticancer Agents in Medical Chemistry 12(1):49-75.

Newman D. J. and Cragg G. M. 2007. Natural products as sources of new drugs over the last 25 years. Journal of Natural Products 70(3):461-77.

Patel S. and Goyal A. 2012. Recent developments in mushrooms as anti-cancer therapeutics: a review 3 Biotech 2(1): 1-15.

Petrova R.D. 2012. New scientific approaches to cancer treatment: can medicinal mushrooms defeat the curse of the century? International Journal of Medicinal Mushrooms 14:1-20.

Wasser S.P. 2014. Medicinal mushroom science: Current perspectives, advances, evidences, and challenges. Biomedical Journal 37(6):345-56.

WHO. 2012. World Health Organization: Globocan 2012 estimated incidence, mortality and prevalence worldwide in 2012; WHO Press, Geneva, Switzerland, 2- 6.

WHO. 2014. World Health Organization: World Cancer Report 2014. WHO Press, Geneva, Switzerland, Chapter 1.1, 4.7, 5.12 and 5.14.

Wu J.Y., Chen C. H., Chang W. H., Chung K. T., Liu Y. W., Lu F. J. and Chen C. H. 2011. Anti-cancer effects of protein extracts from Calvatia lilacina. Pleurotus ostreatus and Volvariella volvacea. Evidence-Based Complementary and Alternative Medicine 2011:110.

Wu Y. and Wang Y. 2010. Inhibition of Astragalusm embranaceus polysaccharides against liver cancer cell Hep G2. African Journal of Microbiology Research 4:2181-2183.

Yamaguchi Y., Miyahara E. and Hihara J. 2011. Efficacy and safety of orally administered Lentinula edodes mycelia extract for patients undergoing cancer chemotherapy: a pilot study. American Journal of Chinese Medicine 39: 451-9.

Younis A. M., Wu F. S. and El Shikh H.H. 2015. Antimicrobial activity of extracts of the oyster culinary medicinal mushroom Pleurotus ostreatus (Higher Basidiomycetes) and identification of a new antimicrobial compound. International Journal of Medicinal mushrooms 17(6):579-90.

Younis A. Stewart J., Wu F. S., El Shikh H., Hassan F. and Elaasser M. 2014a. Effectiveness of different solvents extracts from edible mushrooms in inhibiting the growth of tumor cells. Cancer Biology 4(4): 1-15.

Younis, A. Stewart, J., Wu F.S., El Shikh H., Hassan F. and Elaasser, M. (2014b) Cytotoxic activity of edible mushrooms extracts against tumor cell lines. The International Journal of Science and Technology 3 (11): 736-749.

Zhang Z., Lv G., Pan H., Pandey A., He W. and Fan L. 2012. Antioxidant and hepatoprotective potential of endo-polysaccharides from Hericium erinaceus grown on tofu whey. Intentional Journal of Biological Macromolecules 51(5):1140-6. 